\title{
Knowledge of Physiotherapy in the Prevention and Treatment of Soccer Injuries Among Managers of Amateur Soccer Teams
}

\author{
Gbadamosi, Z.O., ${ }^{1}$ Mohammed, J., ${ }^{2,3}$ Sumaila, F.G. ${ }^{2}$ \\ ${ }^{1}$ Department of Physiotherapy, University of Ilorin Teaching Hospital, Ilorin, Nigeria \\ ${ }^{2}$ Department of Physiotherapy, Bayero University Kano, Kano, Nigeria \\ ${ }^{3}$ Department of Rehabilitation Sciences and Physiotherapy, Ghent University, Gent, Belgium \\ Correspondence \\ Farida Garba Sumaila, Department of Physiotherapy, Bayero University Kano, Kano, Nigeria - E-mail: \\ fareedat2006@gmail.com
}

\begin{abstract}
SUMMARY
This study was designed to evaluate the knowledge of physiotherapy among managers of amateur soccer teams in preventing and treating soccer injuries.

A total of 32 amateur soccer team managers from Kano State, Nigeria were purposively recruited to participate in this study. Thereafter, a questionnaire seeking information on physiotherapy was administered. Data retrieved from the questionnaires were analysed using descriptive statistics of frequencies and percentages.

The results of the study revealed that the average age of the participants was $47 \pm 8$ years. The results also indicated that the majority $(94 \%)$ of the participants were male, and $63 \%$ had post-secondary school qualifications. Working experience was generally low, mostly between one and two years. All the participants demonstrated good knowledge of the role of physiotherapy in preventing injuries (warm up and cool down exercises), as well as the means (use of exercise therapy and massage), indications (sprains, strains and back pain) and the modalities (ice sprays, exercise modalities and bandages). The major areas where lack of knowledge was evident were in the use of strapping $(43.7 \%)$, the role of physiotherapy in health education $(43.7 \%)$, and the use of electrical currents in physiotherapy $(68.7 \%)$. The overall results showed that the average knowledge of the participants regarding the role of physiotherapy in preventing and treating soccer injuries was high $(86.5 \%)$.

It was concluded that a significant proportion of the managers of amateur soccer teams in Kano State have good knowledge of the use of physiotherapy in preventing and treating soccer injuries.
\end{abstract}

KEY WORDS: team managers, amateur soccer, knowledge, physical therapy

\section{INTRODUCTION}

Soccer is an extremely popular, high speed, contact sport that is enjoyed by millions worldwide (Okolie-Osemene and Okoh, 2014). However, the risk of injury in soccer is high, and it is mostly due to trauma on the field of play or during training sessions, as a result of players colliding or falling awkwardly while tackling an opponent (Hamzat et al., 2004; Junge et al., 2002; Matser et al., 1999).
Amateur soccer is highly competitive because millions of players play at this level. Consequently, soccer team managers, coaches and other staff that make up the administration of amateur soccer teams place much emphasis on their players producing positive results and maintaining a high level of participation. Even though the labour market for this category of soccer is relatively flexible compared to soccer at the professional level (Rosen 
and Sanderson, 2001; McGovern, 2002), the soccer team managers at this level are also under significant pressure to succeed.

Traditionally, the roles of soccer team managers include planning, training, organizing, leading, and evaluating the performance of the entire soccer team periodically (Horch and Schutte, 2003; Kelly 2008). Unfortunately, most soccer team managers lack any formal management training and know-how of various other support areas required for comprehensive team success (Kelly, 2008). Additionally, lack of formal training may be more prevalent among amateur soccer team managers.

Generally, the authority of the soccer team managers is largely based on traditional forms of authoritarianism, which allow them to have an unusually high degree of autonomy in defining their own role, and in appointing their support staff (Kelly, 2008). Consequently, soccer team managers are at the receiving end in the event of team failure (Cunningham, 2002).

Physiotherapy has become an essential part of the sports medicine team (Grant et al., 2014), and physiotherapists are reported to play an important role in soccer teams (Twizere, 2004; Mortha, 2009). Specifically, the role of physiotherapy in soccer and other similar sports include, the provision of assistance in minimizing and preventing injuries, rehabilitation of injured players, institution of programmes for enhancing performance, and intervention in cases of injuries during sports (Söderman et al., 2000; McLean, 2014)[1990 in reference list]. The commonly used physiotherapy techniques in soccer include, stretching, massage, immobilization, pain management, muscle conditioning, joint and soft tissue exercises, neuromuscular control (balance and proprioception) training, functional exercises, cardiovascular exercises, and correction of abnormal biomechanics (Mortha, 2009; Söderman, 2000; Mclean, 2014; Andersen, 2005; Faigenbaum et al., 2006).

It is not widely reported whether the knowledge of physiotherapy procedures among soccer team managers can influence the success rates of their teams. However, a poor knowledge of vital physiotherapy care and other factors among officials may affect the output of players (Yakasai and David, 2011; Crossman, 2001). Moreover, there are accounts of soccer players returning to play too early or prior to comprehensive recovery (Podlog and Eklund 2007; Crossman, 2001). There is a paucity of information on sports management in Nigeria. To the best of the knowledge of the present authors, there has been no investigations into the knowledge of amateur soccer team managers about physiotherapy. Therefore, the aim of this study is to investigate the knowledge of physiotherapy among managers of amateur soccer teams.

\section{METHODOLOGY}

\section{Subjects}

This is a descriptive survey research design. The population of the study comprises all managers of amateur soccer teams that are recognized and registered with the Ministry of Sports and Youth Development in Kano State, Nigeria.

\section{Procedure}

Initially, all soccer teams were identified from a list of teams registered with the Ministry of Sports and Youth Development in Kano State. Thereafter, the amateur soccer teams were separated from the elite/professional soccer teams. The sample of amateur soccer team managers that participated in the study were purposively selected based on the following inclusion criteria: that the teams they are managing have been actively participating in tournaments or friendly matches for at least one year non-stop, that the team manager is completely in charge of running the affairs of the team, and that both the managers and the soccer teams have verifiable contacts.

Additionally, official permission was sought and obtained from the Kano State Football Association. The study participants were contacted either at their various club offices or during soccer matches for administration of the study questionnaire. All the participants gave written consent before completing the study questionnaire. The data obtained from the questionnaire was analysed by descriptive statistics using the Statistical Package for the Social Sciences (SPSS) version 16.

\section{Questionnaire description}

The questionnaire used in this study was adopted from the one used by Mortha (2009). It comprised closed and openended questions. The questionnaire has two sections: Section A sought demographic information on the participants, including age, years of experience, gender, and educational qualifications. Section B contained 23 questions, which tested the participants' knowledge of physiotherapy relating to soccer across four domains: preventive techniques, means of treatment, indications, and 
modalities used in physiotherapy. Only Section A was modified to suit this study.

\section{Scoring of the Questionnaire}

All the correct responses in the questionnaire were scored one (1) point, while incorrect responses were scored zero. The highest possible score was 23 points. The total score of the participants was then converted to percentages. Thereafter, the overall knowledge score was described based on the percentages in three categories. A score less than $40 \%$ connoted poor knowledge, $41-60 \%$ connoted fair knowledge while a score of $60 \%$ and above indicated good knowledge

\section{RESULTS}

Initially, 40 amateur soccer team managers that met the inclusion criteria participated in the study. However, only 32 questionnaires were properly completed and returned. The analysis and presentation of the results of this study are based on these. Table 1 shows the demographic characteristics of the participants. The majority (94\%) of the amateur team managers were male. The results also show that the mean age of the participants was $47(\mathrm{SD} \pm 8$ ) years and about $63 \%$ had post-secondary qualifications. The majority $(87.5 \%)$ of the participants had only a few years of experience (between 1 and 2 years). Lastly, the results also show that $18(56.3 \%)$ of the participants reported availability and access to physiotherapy services.

Table 2 presents the results of the questions assessing the knowledge of physiotherapy among the participants across the four domains (prevention, means, indication and modalities) of the questionnaire. The results reveal that all the participants $(100 \%)$ demonstrated good knowledge of the importance of injury prevention techniques such as: warming up, cooling down, achieving full recovery, and taking precautionary measures during injury. However, only $68.7 \%$ and $56.3 \%$ of the participants agreed that physiotherapists have a role in injury prevention and that strapping has a role in preventing injuries respectively. The results further reveal that the majority of the participants had good knowledge of means of physiotherapy intervention such as: exercise therapy (100\%), massage (93.7\%), and drug prescription (100\%). A lower number of participants recorded correct responses for the means of physiotherapy to include physical education $(56.3 \%)$ and surgical operation $(32.3 \%)$.
Table 1. Sociodemographic data of the participants

\begin{tabular}{|c|c|c|c|}
\hline Variables & $\mathrm{M}(\mathrm{SD})$ & & $\mathrm{n}(\%)$ \\
\hline Age & $47(8)$ & & \\
\hline \multirow{2}{*}{\multicolumn{2}{|c|}{ Gender }} & Male & $30(93.7)$ \\
\hline & & Female & $2(6.3)$ \\
\hline \multirow{2}{*}{\multicolumn{2}{|c|}{ Number of teams ever managed }} & One & $16(50)$ \\
\hline & & Two & $16(50)$ \\
\hline \multirow{4}{*}{\multicolumn{2}{|c|}{ Highest educational qualification }} & No formal & $0(0)$ \\
\hline & & Primary & $1(3.1)$ \\
\hline & & Secondary & $11(34.4)$ \\
\hline & & Tertiary & $20(62.5)$ \\
\hline \multirow{3}{*}{\multicolumn{2}{|c|}{ Experience as soccer team manager }} & $<12$ months & $2(6.3)$ \\
\hline & & $1-2$ years & $28(87.5)$ \\
\hline & & $>2$ years & $2(6.3)$ \\
\hline \multirow{2}{*}{\multicolumn{2}{|c|}{ Access to physiotherapy services }} & Yes & $18(56.3)$ \\
\hline & & No & $14(43.7)$ \\
\hline
\end{tabular}

Table 2. Team managers' knowledge of physiotherapy

\begin{tabular}{|c|c|c|}
\hline Questions & $\begin{array}{c}\text { Correct response } \\
\mathrm{n}(\%)\end{array}$ & $\begin{array}{c}\text { Incorrect response } \\
\mathrm{n}(\%)\end{array}$ \\
\hline \multicolumn{3}{|l|}{ Preventive injuries } \\
\hline Warming up and training & $32(100)$ & $0(0)$ \\
\hline Cooling down exercises & $32(100)$ & $0(0)$ \\
\hline Strapping of joints & $18(56.3)$ & $14(43.7)$ \\
\hline Precaution during recovery & $32(100)$ & $0(0)$ \\
\hline Playing with injury & $32(100)$ & $0(0)$ \\
\hline Physiotherapist as trainer & $22(68.7)$ & $10(32.3)$ \\
\hline \multicolumn{3}{|l|}{ Means of treatment } \\
\hline Massage & $30(93.7)$ & $2(6.3)$ \\
\hline Exercise therapy & $32(100)$ & $0(0)$ \\
\hline Health education & $18(56.3)$ & $14(43.7)$ \\
\hline Drug medication & $32(100)$ & $0(0)$ \\
\hline Surgical operation & $22(68.7)$ & $10(32.3)$ \\
\hline \multicolumn{3}{|l|}{ Indication for treatment } \\
\hline Fracture & $24(75)$ & $8(25)$ \\
\hline Stomach pain & $26(81.2)$ & $6(18.8)$ \\
\hline Sprain (ligamentous) & $32(100)$ & $0(0)$ \\
\hline Muscle strain & $32(100)$ & $0(0)$ \\
\hline Joint pain & $28(87.5)$ & $4(12.5)$ \\
\hline Back pain & $32(1000$ & $0(0)$ \\
\hline \multicolumn{3}{|l|}{ Modalities used in physiotherapy } \\
\hline Ice/ice sprays & $32(100)$ & $0(0)$ \\
\hline Braces & $26(81.2)$ & $6(18.8)$ \\
\hline Cycle ergometer/treadmill & $32(100)$ & $0(0)$ \\
\hline Electrical stimulus (stimulator) & $10(32.3)$ & $22(68.7)$ \\
\hline Couches & $28(87.5)$ & $4(12.5)$ \\
\hline Bandages & $32(100)$ & $0(0)$ \\
\hline
\end{tabular}


Furthermore, the results show that all the participants $(100 \%)$ agreed that conditions for which physiotherapy is indicated include ligamentous sprain, muscle strain, and back pain. However, about $25 \%$ and $18.8 \%$ reported that physiotherapy has a role in the management of fractures and stomach pain, respectively. The participants also performed well in the questions regarding modalities used in physiotherapy. They all agreed that cycle ergometer/treadmill, ice sprays, and bandages are modalities used by physiotherapists in managing soccer injuries. The participants also gave correct responses regarding other modalities such as braces $(81.2 \%)$ and couches $(87.5 \%)$. However, the use of electrical current in physiotherapy recorded poor knowledge, since only $32.3 \%$ recognized it as a physiotherapy modality.

Lastly, the overall average score on knowledge of physiotherapy among the participants was $86.5 \%$.

\section{DISCUSSION}

This study was conducted to evaluate the knowledge of the role of physiotherapy in preventing and treating soccer injuries among managers of amateur soccer teams in Kano State. This study is the first attempt at focusing on the knowledge of this topic among managers of amateur soccer teams. Assessing the knowledge of managers will no doubt have a positive impact on the performance of soccer clubs at sub-elite levels.

Most of the participants in this study were male and this finding is consistent with past studies that have revealed soccer team management to be a male-dominated profession, even in female soccer teams (Connel and Messcherschmidt, 2005; Shaw, 2006; Skille, 2014). In addition, soccer is traditionally considered a masculine sport in most parts of the world, especially in developing countries. The results of this study show that most of the participants demonstrated good knowledge of the role of physiotherapy in preventing and treating soccer injuries. The average knowledge exhibited among the participants in this study was high compared to that of a previous study by Mortha (2009) among managers of soccer teams in the South African premier league. This could be attributed to the fact that a significant percentage of participants in this study had post-secondary/tertiary qualifications. Furthermore, global awareness of physiotherapy has been on the increase in recent years.
This study highlights the importance of standard qualifications in sports management. Previous studies have recommended that sports management qualifications should extend to areas such as marketing, finance, information management, human resource management, and economics (Horch and Schutte, 2003; Force, 1993). In addition, the results also show that most of the participants had between one and two years working experience as managers, indicating that they were at the nascent stage of their managerial career. Surprisingly, in spite of this, a high level of knowledge was reported. Furthermore, it is plausible that, if given the opportunity, most managers of amateur soccer teams will transfer their services to elite/professional teams, which are more lucrative and prestigious. This may explain the low number of participants in the present study and their limited work experience.

Generally, the cost of retaining a physiotherapist is high (Mitchell et al., 2005). The scarcity of physiotherapy services makes them expensive, and physiotherapists may prefer to work in more professional teams, which may explain the limited access to physiotherapy services by many amateur soccer teams (Frantz, 2007). Unfortunately, this could lead to seeking alternatives that might prove inimical in the long-run. Since injuries remain the biggest challenge at all levels of soccer (Heidt et al., 2000; Verhagen et al., 2005; Azubuike and Okojie, 2009), it is vital that managers of amateur soccer teams have good knowledge of the role of physiotherapy in preventing and treating soccer injuries as this may prove very useful in their future careers.

This study had a few limitations: (i) the analysis did not take into account the influence of educational qualification and access to physiotherapy services as reported by participants on their knowledge of the role of physiotherapy in preventing and treating soccer injuries. However, this is not likely to affect the results going by the overwhelmingly accurate responses to most of the questions, and (ii) the study instrument adopted mostly asked for information about basic physiotherapy procedures and roles. Consequently, the findings can only apply to this extent. However, these results are promising and relevant because managers of soccer teams are not required by convention and practice to have knowledge of advanced techniques and roles of physiotherapy in preventing and treating soccer injuries. 
Based on the findings of this study, it can be inferred that good knowledge of the role of physiotherapy in preventing and treating soccer injuries, which has been widely reported to be of significant economic and social impact in soccer, may be associated with the performance of amateur soccer players. However, further studies are needed to prove this. For now, it is recommended that physiotherapy services be made more accessible to amateur soccer teams.

\section{CONCLUSION}

It was concluded that a large proportion of managers of amateur soccer teams in Kano State have good knowledge of the role of physiotherapy in preventing and treating soccer injuries.

\section{Acknowledgement}

The authors express their gratitude to the Kano State Football Association for their cooperation in accessing the participants of this study.

\section{References}

Andersen J.C. 2005. Stretching before and after exercise: Effect on muscle soreness and injury risk. Journal of Athletic Training 40(3): 218.

Azubuike, S.O. and Okojie, O.H. 2009. An epidemiological study of football (soccer) injuries in Benin City, Nigeria. British Journal of Sports Medicine 43(5): 382-386.

Connell, R.W. and Messerschmidt, J.W. 2005. Hegemonic masculinity rethinking the concept. Gender \& Society 19(6): 829-859.

Crossman J. 2001. Coping with Sports Injuries: Psychological strategies for rehabilitation. New York: Oxford University Press.

Cunningham A. 2002. An audit of first aid qualifications and knowledge among team officials in two English youth football leagues: A preliminary study. British Journal of Sports Medicine 36(4): 295-300.

Faigenbaum A.D., McFarland J.E., Schwerdtman J.A., Ratamess N.A., Kang J. and Hoffman J.R. 2006. Dynamic warm-up protocols, with and without a weighted vest, and fitness performance in high school female athletes. Journal of Athletic Training 41(4): 357.

Force N.N.J.T. 1993. Standards for curriculum and voluntary accreditation of sport management education programs. Journal of Sport Management 159: 170.
Frantz J.M. 2007. Challenges facing physiotherapy education in Africa.

Grant M.E., Steffen K., Glasgow P., Phillips N., Booth L., and Galligan M. 2014. The role of sports physiotherapy at the London 2012 Olympic Games. British Journal of Sports Medicine 48(1): 63-70.

Hamzat T.K., Adeniyi A. F., Awolola O.E., and Olaleye O. A. 2004. Injury pattern of FIFA, CAF and UEFA soccer tournaments: A retrospective study of selected 2002 matches. South African Journal of Physiotherapy 60(3): 10-14.

Heidt R.S., Sweeterman L.M., Carlonas R.L., Traub J.A., and Tekulve F.X. 2000. Avoidance of soccer injuries with preseason conditioning. The American Journal of Sports Medicine 28(5): 659-662.

Horch H.D. and Schütte N. 2003. Competencies of sport managers in German sport clubs and sport federations. Managing Leisure 8(2): 70-84.

Junge A., Rösch D., Peterson L., Graf-Baumann T., and Dvorak J. 2002. Prevention of soccer injuries: a prospective intervention study in youth amateur players. The American Journal of Sports Medicine 30(5): 652-659.

Kelly S. 2008. Understanding the role of the football manager in Britain and Ireland: A Weberian approach. European Sport Management Quarterly 8(4): 399-419.

Matser E.J., Kessels A.G., Lezak M.D., Jordan B.D. and Troost J. 1999. Neuropsychological impairment in amateur soccer players. JAMA 282(10): 971-973.

McGovern P. Globalization or internationalization? Foreign footballers in the English league, 1946-95. Sociology 2002; 36(1): 23-42.

McLean D.A. Role of the team physiotherapist in rugby union football. British Journal of Sports Medicine 1990; 24(1): 1924.

Mitchell C., Walker J., Walters S., Morgan A.B., Binns T. and Mathers N. 2005. Costs and effectiveness of pre and post operative home physiotherapy for total knee replacement: randomized controlled trial. Journal of Evaluation in Clinical Practice 11(3): 283-292.

Motha S.G. Team Managers' Knowledge of the Role of Physiotherapy in South African Soccer Teams in the Premier Soccer League. Doctoral dissertation, University of Limpopo (Medunsa Campus).

Okolie-Osemene J. and Okoh R.I. 2014. The role of Nigeria Football Federation in the denouement of premier league seasonal disputes: Issues and prospects. Recreation and Society in Africa, Asia and Latin America 5(1).

Podlog L. and Eklund R.C. 2007. The psychosocial aspects of a return to sport following serious injury: A review of the literature from a self-determination perspective. Psychology of Sport and Exercise 8(4): 535-566. 
Rosen S. and Sanderson A. 2001. Labor markets in professional sports. The Economic Journal 111(469): 47-68.

Shaw S. 2001. Scratching the back of "Mr X": Analyzing gendered social processes in sport organizations. Journal of Sport Management 20(4): 510.

Skille E.Å. 2014. Sport in the welfare state-Still a male preserve: A theoretical analysis of Norwegian football management. EJSS. European Journal for Sport and Society 11(4): 389.

Söderman K., Werner S., Pietilä T., Engström B. and Alfredson H. 2000. Balance board training: Prevention of traumatic injuries of the lower extremities in female soccer players? Knee Surgery, Sports Traumatology, Arthroscopy 8(6): 356-363.

Twizere, J. 2004. Epidemiology of soccer injuries in Rwanda: $A$ need for physiotherapy intervention (Doctoral dissertation, University of the Western Cape).

Verhagen E.A.L.M., Van Tulder M., van der Beek A.J., Bouter L.M. and van Mechelen W. 2005. An economic evaluation of a proprioceptive balance board training programme for the prevention of ankle sprains in volleyball. British Journal of Sports Medicine 39(2): 111-115.

Yakasai M.G. and David R. 2011. Technical deficiency as a factor responsible for low performance of super falcons of Nigeria in Olympics and World Cup football competitions, 1991-2010. International Journal of Sports Sciences \& Fitness 1(2). 